\title{
Effect of the Initial Air Content in Fresh Slurry on the Compressive Strength of Hardened Cemented Paste Backfill
}

\author{
Youzhi Zhang $\mathbb{D}^{1},{ }^{1}$ Deqing Gan $\mathbb{D}^{1},{ }^{1}$ Zhenlin Xue, ${ }^{1}$ Xun Chen, ${ }^{2}$ and Sheng $\mathrm{Hu}^{2}$ \\ ${ }^{1}$ College of Mining Engineering, North China University of Science and Technology, Tangshan 063210, China \\ ${ }^{2}$ School of Civil and Resource Engineering, University of Science and Technology Beijing, Beijing 100083, China \\ Correspondence should be addressed to Deqing Gan; 17330544396@163.com
}

Received 24 September 2020; Revised 27 October 2020; Accepted 29 October 2020; Published 12 November 2020

Academic Editor: Erol Yilmaz

Copyright (C) 2020 Youzhi Zhang et al. This is an open access article distributed under the Creative Commons Attribution License, which permits unrestricted use, distribution, and reproduction in any medium, provided the original work is properly cited.

Filling mining method can dispose of the tailings into filling slurry, which can be transported to the stope through pipelines to manage the ground pressure and protect the environment. To improve the flowability of filling slurry, additives are used more and more widely. However, some additives can increase the air content in the slurry. The air in the slurry will become pores in the hardened cemented paste backfill (CPB). Therefore, it is necessary to explore the influence of initial air content in fresh slurry on the compressive strength of CPB. In this paper, sodium dodecyl sulfate (SDS) was used to regulate the air content in the fresh slurry. After measuring the initial air content, the slurry was made into test blocks. Then, the uniaxial compressive strength (UCS) of $\mathrm{CPB}$ at $28 \mathrm{~d}$ age was tested, and the distribution of CPB microscopic pores was observed by scanning electron microscope (SEM). The results show that as the initial air content in fresh slurry increases, the UCS of CPB first increases and then decreases. Before the initial air content in fresh slurry is $6.03 \%$, the CPB pores distribution is relatively uniform. However, after exceeding this value, "discontinuous contact" structures, pore groups, and macropores occur in CPB. Through the CPB microscopic force analysis, the mathematical model describing the effect of initial air content on UCS of CPB should be a combination of logarithmic function and quadratic polynomial. This work can provide a supplement to the theory of CPB strength.

\section{Introduction}

Filling mining method can discharge all or most of the tailings into the underground stope, which can not only effectively manage the ground pressure of stope, but also relieve the environmental and economic pressure of tailings surface depositing [1-7]. Under this background, the mechanical properties (i.e., compressive strength, tensile strength, and flexural strength) of cemented paste backfill (CPB) have attracted wide attention. The compressive strength is the most concerned property among all of them [8-10]. Generally, filling slurry is composed of aggregates, binders, water, and other additives [11]. After stirring by a mixer, the slurry will contain a certain amount of air, so that there will be some pores in the hardened CPB $[12,13]$. The slurry is transported into the stope through a pipeline, so the slurry flowability has an important influence on the filling mining efficiency. Low-concentration slurry has good flowability, but the strength of hardened CPB is poor (caused by cement segregation). High-concentration slurry can effectively improve the $\mathrm{CPB}$ strength, but the flowability is poor. In order to improve the flowability of high-concentration slurry, pumping agents are widely used in slurry pipeline transportation. The pumping agent is generally mainly composed of water-reducing agent and airentraining agent (AEA). Air-entraining agent will increase the air content (the percentage in air volume/total slurry volume) in the slurry, thereby increasing the pores in the $\mathrm{CPB}$, which will have a certain impact on the $\mathrm{CPB}$ strength $[14,15]$.

Traditional studies on initial air content in fresh slurry tend to focus on its influence on material durability, frost resistance, and thermal conductivity of concrete or $\mathrm{CPB}$ [16-18]. However, in recent years, scholars have also carried out a large number of studies to investigate the relationship between initial air content and compressive strength of 
concrete or $\mathrm{CPB}$. In the first place, according to chemical composition, AEA can be divided into type rosin, alkyl, saponins, etc. The air entrainment effect of different AEA is different, and the AEA dosage for different properties of materials (i.e., surface chemical properties of materials, grain size distribution, and the concentration of slurry) is also different [19]. Secondly, literatures [20,21] showed that the pores in CPB introduced by surfactants or hydrolyzed protein solutions are usually in the micron range, and the size, spacing, and connectivity of the pores are also important. Besides, Özcan and Emin Koç [22] used image processing technology to find that the compressive strength of aerated concrete is inversely proportional to the air content of the fresh slurry and the pores area of the hardened concrete cutting surface. On the contrary, Hilal et al. [23] believed that although some additives increased the porosity of the concrete cutting surface, they achieved higher strength due to the reduced connectivity.

It can be seen that past researches have analyzed the relationship between porosity and compressive strength from a qualitative perspective. However, they did not propose a mathematical model that can use the initial air content in fresh slurry to quantitatively analyze the $\mathrm{CPB}$ strength. In engineering, it is easier to test the initial air content in a fresh slurry, but it is relatively difficult to test the porosity of CPB. Therefore, this paper will carry out the experimental research on the effect of initial air content in fresh slurry on the UCS of CPB. Combined with the $\mathrm{CPB}$ microscopic force analysis under compression, a quantitative mathematical model will be proposed. This work will make a useful supplement to the theory of CPB strength.

\section{Materials and Methods}

2.1. Materials and Equipment. The full tailings are taken from an iron ore tailings reservoir in Hebei Province, China. The particle size distribution curve of full tailings is shown in Figure 1. The important tailings particle size parameters are as follows: $\mathrm{d}(\mathrm{av})=37.58 \mu \mathrm{m}, \mathrm{d}(50)=20.33 \mu \mathrm{m}$, and $\mathrm{d}(90)=$ $98.96 \mu \mathrm{m}$. The specific gravity is $2.62 \mathrm{~g} \cdot \mathrm{cm}^{-3}$. The chemical composition analysis of full tailings is shown in Table 1 . The cementing agent is Portland slag cement P.S.A 32.5 (granulated blast furnace slag accounts for 50\%). The water is ordinary city tap water, and AEA is sodium dodecyl sulfate (SDS), which belongs to the type alkyl. The CA-3 digital concrete air content tester, with a range of $10 \%$, was used to test the air content in fresh slurry. For the observation of the CPB microstructure, the JEOL JSM-6390A scanning electron microscope (SEM) was selected. The uniaxial compressive strength (UCS) test adopted the WHY-600 singleaxis press with a range of $600 \mathrm{kN}$ and an accuracy of $0.01 \mathrm{kN}$.

The components of the air content tester are shown in Figure 2. The first step when measuring is to put the fresh slurry into the device and then use a vibrating table to vibrate to a dense state (the frequency of the vibrating table is $50 \mathrm{~Hz}$ ). If the slurry is lower than the bottom chamber sealing plane, it should be added to be a little higher than the sealing plane. After vibrating again, use a scraper to scrape off the excess slurry on the sealing surface. Next, close the lid,

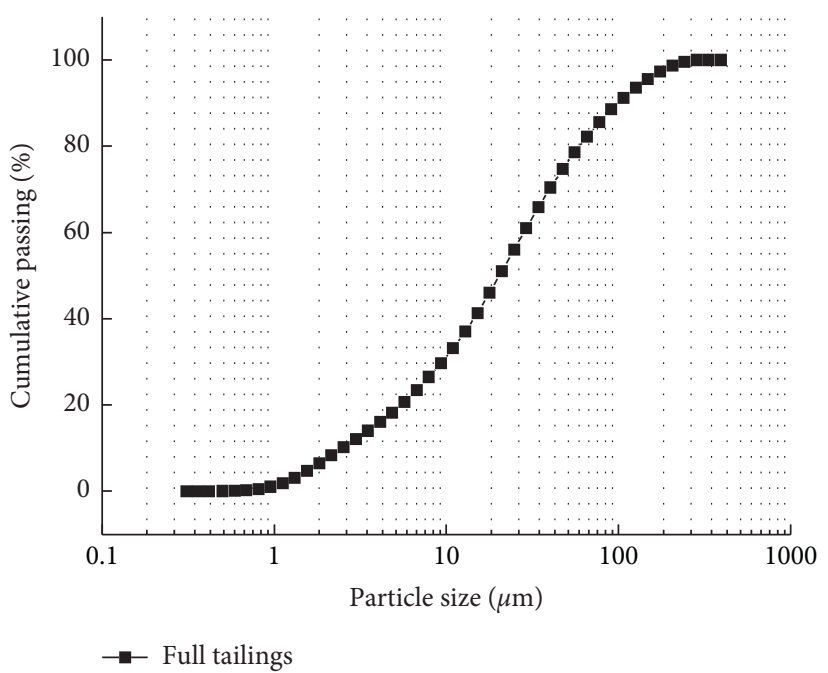

Figure 1: Particle size distribution curve of full tailings.

TABLE 1: Chemical composition of full tailings

\begin{tabular}{lcccccc}
\hline Component & $\mathrm{TFe}$ & $\mathrm{SiO}_{2}$ & $\mathrm{CaO}$ & $\mathrm{MgO}$ & $\mathrm{Al}_{2} \mathrm{O}_{3}$ & Others \\
\hline Content (\%) & 4.29 & 74.24 & 2.96 & 3.34 & 7.65 & 7.52 \\
\hline
\end{tabular}

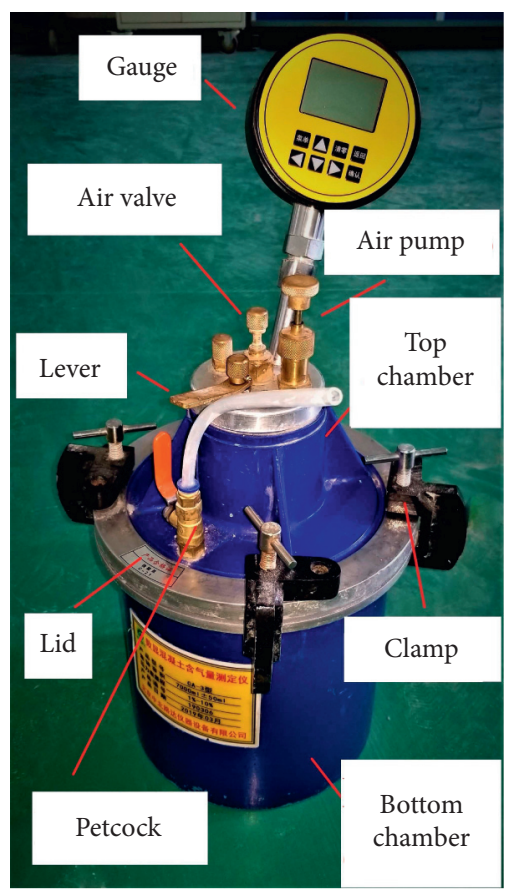

FIgURe 2: Air content tester for fresh slurry.

and clamp it with clamps. A bubble level is used to check the device. Then, open the petcock to fill water, and close the petcock and air valve when the water flows out from the air valve. Next, pressurize to $0.1 \mathrm{MPa}$ with an air pump. Then, press the lever 2-3 times, and use a wooden hammer to hit the bottom chamber to distribute the pressure evenly to all parts of the sample. The gauge can directly display the air content value. When the data in the gauge is stable, record 
the air content value. A calibration experiment is needed before the formal experiment. Each experiment is executed twice. If the measured values differ by more than $0.5 \%$, a new experiment is needed. Until the measured values differ by less than $0.5 \%$, take the average value as the final value.

2.2. Test Scheme. In this study, the mass concentration of slurry used in the experiment was set to $70 \%$, and the cement/sand ratio was $1: 4$. The volume of the air content tester bottom chamber is $7 \mathrm{~L}$. Considering the richness factor, the volume of slurry in each experiment was set at 7.5 L. SDS was added to water to complete dissolution, and then the tailings, cement, and water were mixed in a mixing tank for 1 minute to ensure the slurry uniform preparation. The SDS dosage was set to $0.01 \%-0.06 \%$ of the quality of cement, and we set up a control experiment without SDS. Since it usually takes 3-5 minutes for the slurry from the mixing tank to filling drilling in a mine, the air content test is carried out 3 minutes after the slurry is prepared. Then, the slurry was made into $70.7 \times 70.7 \times 70.7 \mathrm{~mm}$ standard test blocks (Chinese industry-standard, JGJ/T70-2009). Each slurry was made into 6 blocks. After 24 hours, the mold was removed, and the blocks were put into the curing box. The curing temperature was $20^{\circ} \mathrm{C}$, and the humidity was $90 \%$. When the curing age was $28 \mathrm{~d}$, the UCS test of blocks was carried out. Among the six test blocks, the repeatable test value was considered as the $28 \mathrm{~d}$ strength value. Finally, the SEM experiments were carried out to observe the failure surface. The mixing ratio of fresh filling slurry is shown in Table 2.

\section{Results and Discussion}

3.1. Effect of SDS Dosage on Initial Air Content in Fresh Slurry. According to the test results of each experiment, the relationship between the SDS dosage and the initial air content in fresh slurry is drawn, as shown in Figure 3. It can be seen that the air content in fresh slurry increases steadily with the SDS dosage increase. From experiment A to experiment B, when the SDS dosage is from 0 to $0.01 \%$, the initial air content increases from $2.40 \%$ to $4.62 \%$, with the biggest increase amplitude of $2.22 \%$. From experiment B (air content $4.62 \%$ ) to experiment C (air content $6.03 \%$ ), the increased amplitude is $1.41 \%$, and it is lower than $2.22 \%$. The lowest increase amplitude is $0.58 \%$, which occurs from experiment F (air content 8.31\%) to experiment G (air content $8.89 \%$ ). It is showing an obvious quadratic polynomial relationship between SDS dosage and initial air content. The fitting equation is $y=-1516.7 x^{2}+193.1 x+$ 2.6 ( $x$ represents the SDS dosage, and $y$ represents the initial air content in fresh slurry). The adjustment coefficient of determination $\left(R^{2}\right)$ is 0.9904 , indicating that the fitting equation has high credibility and can truly reflect the effect of SDS dosage on initial air content in a fresh slurry.

3.2. Effect of Initial Air Content on UCS. Figure 4 shows the stress-displacement curve of each experiment in the UCS test when curing for 28 days. The stress-displacement curve of some experiments in Figure 4 shows fluctuation around the peak value. This phenomenon is caused by local pores collapse when the test block is compressed under the conditions of constant loading rate and random pore distribution. In the vicinity of the pores, where the stress concentration is high, the particle bonding contact loss leads to local softening and collapse. This collapse will cause local densification, thereby hardening the material and increasing the stress. After the sample is compacted, the stress concentration will appear in another new position until it forms new cracks. This process may be repeated two or more times, then several macroscopic cracks are formed, resulting in complete destruction. Besides, it can be seen from Figure 4 that this kind of fluctuations mostly appeared in experiments A, B, C, and D, and experiments E, F, and G, and by contrast, they are not obvious. The $28 \mathrm{~d}$ age UCS of all test blocks are shown in Figure 5. It can be seen that the strength of the control block is $1.15 \mathrm{MPa}$. The strength of experiment $\mathrm{C}$ (6.03\% initial air content) is the highest, which is $1.54 \mathrm{MPa}$. The strength of experiments $\mathrm{F}$ and G $(8.31 \%$ and $8.89 \%$ initial air content, respectively) is lower than that of the control experiment, while that of the other experiments was between $1.15 \mathrm{MPa}$ and $1.54 \mathrm{MPa}$. It can be seen that the initial air content in fresh slurry has a nonmonotonic effect on the $28 \mathrm{~d}$ age UCS. This result can provide some explanation for the different views of Özcan and Emin Koç [22] and Hilal et al. [23]. For these experimental materials, the initial air content of $6.03 \%$ is the most beneficial to the $28 \mathrm{~d}$ age strength.

\subsection{Effect of Initial Air Content on Pores Distribution.} The SEM photos are shown in Figure 6, which shows that as the initial air content in fresh slurry gradually increases, the pores structure in hardened $28 \mathrm{~d}$ age $\mathrm{CPB}$ is more and more developed. The pores distribution of Figure $6(\mathrm{~b})$ is more uniform than that of the control experiment, shown in Figure 6(a), and the structure formed by calcium silicate hydrate $(\mathrm{C}-\mathrm{S}-\mathrm{H})$ and tailings particles in Figure 6(b) is also denser than that shown in Figures 6(a), 6(c), and 6(d), respectively, representing that the initial air content in fresh slurry is $6.03 \%$ and $6.94 \%$, which are close to three times of the control experiment. After being hardened, the dense area is denser than that of experiments $\mathrm{A}$ and $\mathrm{B}$, but there are already a few large pores formed. Figure 6(e) shows that, due to the increase of the initial air content in fresh slurry, the inside of CPB has shown "discontinuous contact" structures. Figures 6(f) and 6(g) represent that pore groups and macropores begin to appear, and the diameter of the macropore approaches $200 \mu \mathrm{m}$. This is because SDS is an anionic surfactant. When the SDS dosage is small, the entrained bubbles will have a "wall effect" on the surface, which has a certain hindering ability to reduce the bubbles combination. When the dosage increases to a certain value, with too many bubbles entrained, the bubbles begin to break through this "wall effect." They have a tendency to gather together, forming a certain amount of pore groups, and even fusion phenomenon occurs, resulting in large bubbles, which appear as macropores after solidification. The 
TABLE 2: Mixing ratio of the fresh filling slurry.

\begin{tabular}{lcccccccc}
\hline $\begin{array}{l}\text { Serial } \\
\text { number }\end{array}$ & $\begin{array}{c}\text { SDS dosage } \\
(\%)\end{array}$ & $\begin{array}{c}\text { SDS dosage } \\
(\mathrm{g})\end{array}$ & $\begin{array}{c}\text { Cement/sand } \\
\text { ratio }\end{array}$ & $\begin{array}{c}\text { Volume of slurry } \\
(\mathrm{L})\end{array}$ & $\begin{array}{c}\text { Mass concentration } \\
(\%)\end{array}$ & $\begin{array}{c}\text { Cement } \\
(\mathrm{kg})\end{array}$ & $\begin{array}{c}\text { Full tailings } \\
(\mathrm{kg})\end{array}$ & $\begin{array}{c}\text { Water } \\
(\mathrm{kg})\end{array}$ \\
\hline A & 0 & 0 & 0.25 & 7.5 & 70 & 70 & 1.93 & 7.70 \\
B & 0.01 & 0.193 & 0.25 & 7.5 & 7.5 & 70 & 1.93 & 7.70 \\
C & 0.02 & 0.385 & 0.25 & 7.5 & 70 & 4.13 \\
D & 0.03 & 0.578 & 0.25 & 7.5 & 70 & 1.93 & 7.70 \\
E & 0.04 & 0.770 & 0.25 & 7.5 & 70 & 4.13 & 1.93 & 7.70 \\
F & 0.05 & 0.963 & 0.25 & 7.5 & 70 & 4.13 & 7.70 \\
G & 0.06 & 1.155 & 0.25 & & 7.5 & 4.13 & 7.70 \\
\hline
\end{tabular}

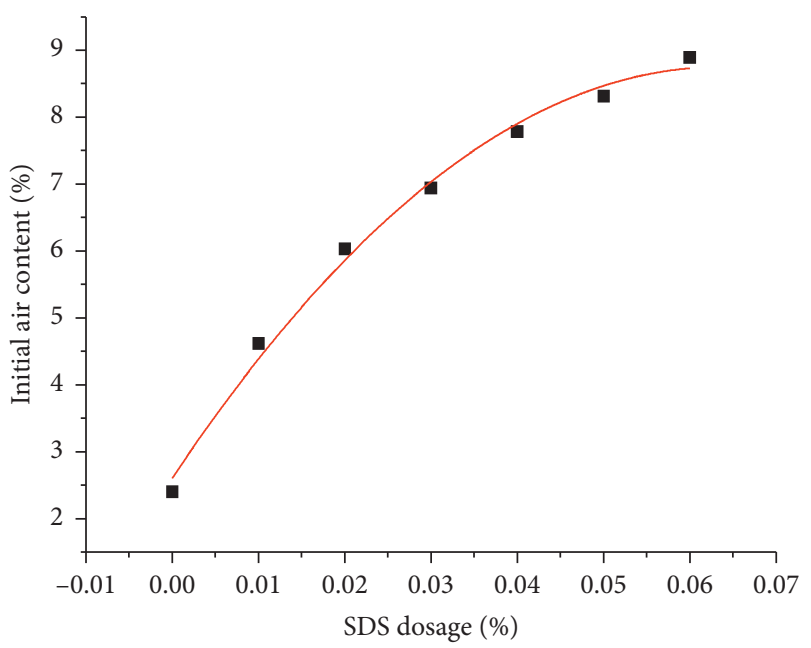

- Initial air content

Fitting curve

FIGURE 3: Relationship between the SDS dosage and the initial air content in fresh slurry.

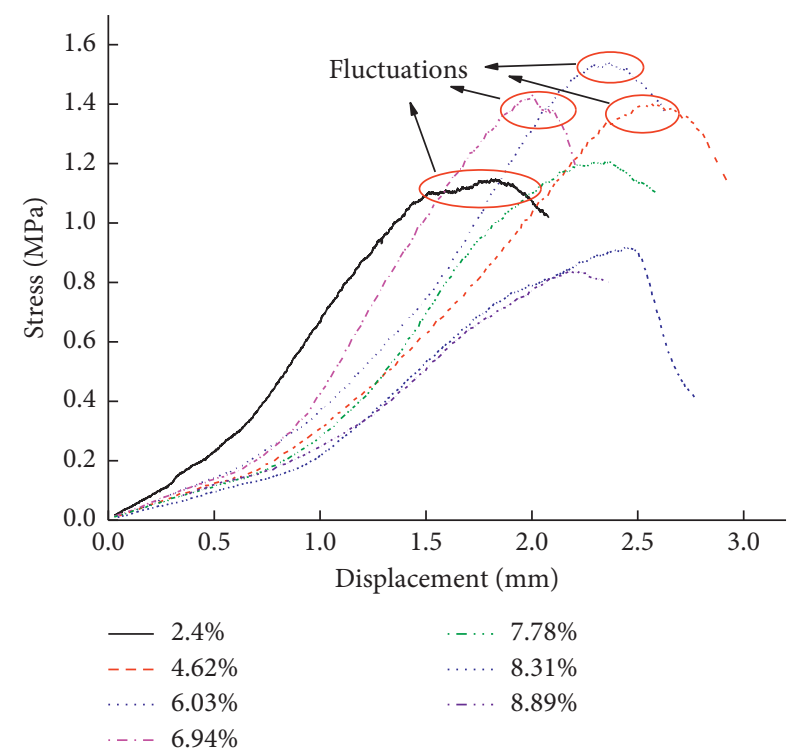

FIgURE 4: Stress-displacement curves of $28 \mathrm{~d}$ age.

"discontinuous contact" structures, pore groups, and macropores will still soften and collapse when the block is compressed, but before compaction occurs, the block has

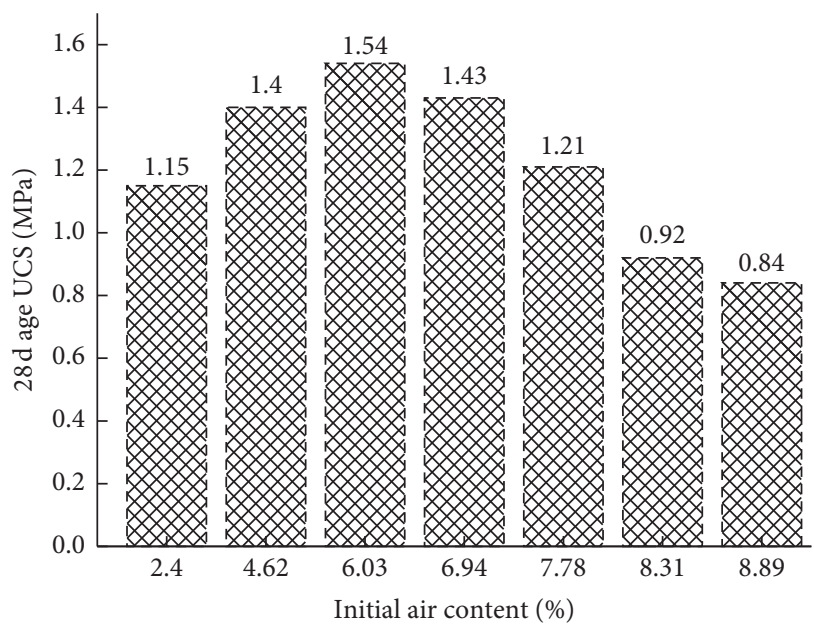

FIGURE 5: The relationship between initial UCS with different initial air content air content and $28 \mathrm{~d}$ age UCS.

lost its load-bearing capacity. This is also the reason why the experimental curves of E, F, and G in Figure 4 have not obvious fluctuations.

3.4. Mathematical Model and Its Evaluation. Given the characteristic that the $28 \mathrm{~d}$ age strength first increases and then decreases with the increase of initial air content, a quadratic polynomial fitting was performed for the $28 \mathrm{~d}$ age strength. The fitting result is $y=-0.052 x^{2}+0.535 x+0.134$ ( $x$ represents initial air content, and $y$ represents $28 \mathrm{~d}$ age UCS), and the $R^{2}$ is 0.889 , which is lower than 0.9 , with low credibility. Therefore, it is necessary to carry out in-depth mechanical analysis to find a mathematical model that can accurately describe the effect of initial air content in fresh slurry on $28 \mathrm{~d}$ age UCS.

The hardened CPB can be simplified into the following model [24]: (i) Tiny particles gather together to form a unitbody; (ii) The gaps between the particles are filled with C-S$\mathrm{H}$; (iii) Numerous unit-bodies constitute the entire CPB. The macroscopic mechanical properties of CPB are the sum of the unit-bodies mechanical properties. Figure 7 shows the contact relationship between the particles in the unit-body when the $\mathrm{CPB}$ is compressed.

Figure 7(a) is a unit-body. A fixed particle $i$ in the unitbody will have a contact relationship with multiple particles. According to Newton's second law, the equation of motion can be described as 


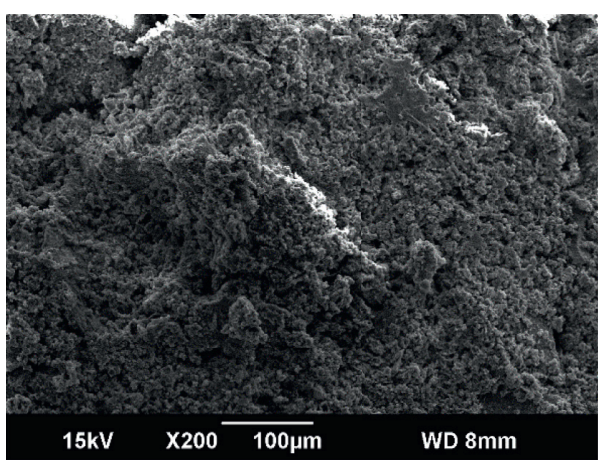

(a)

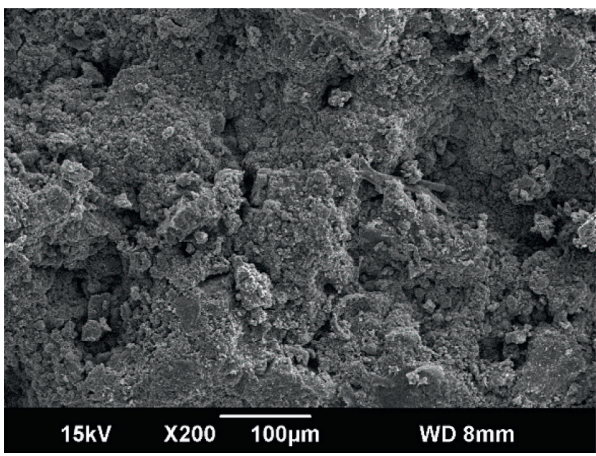

(c)

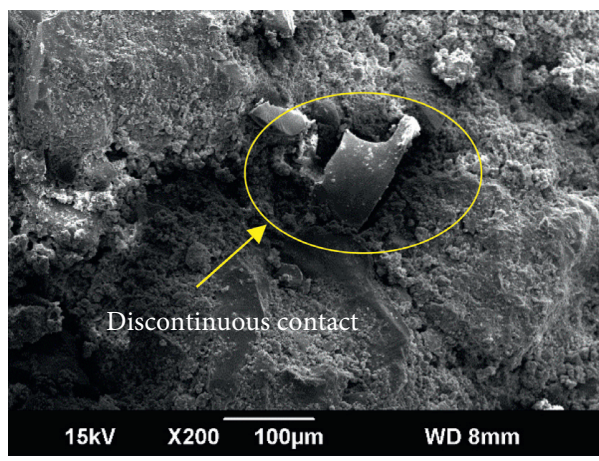

(e)

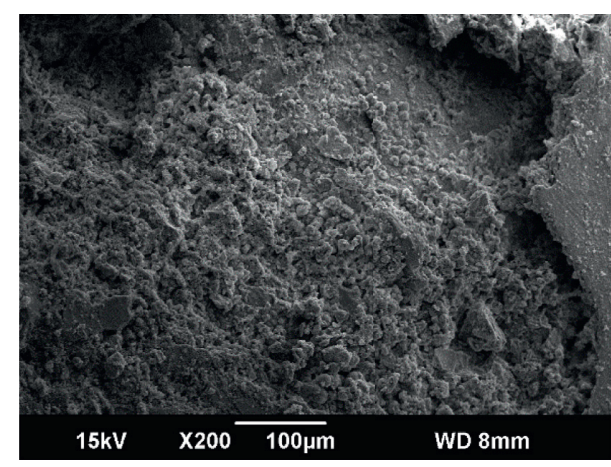

(b)

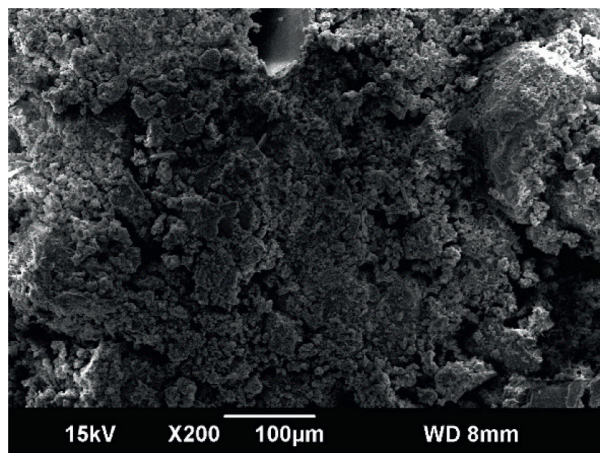

(d)

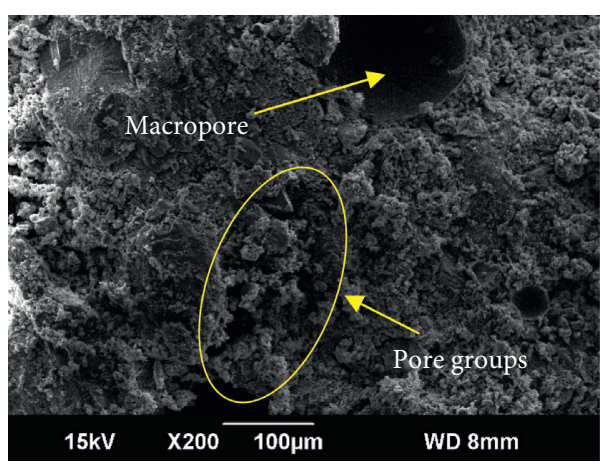

(f)

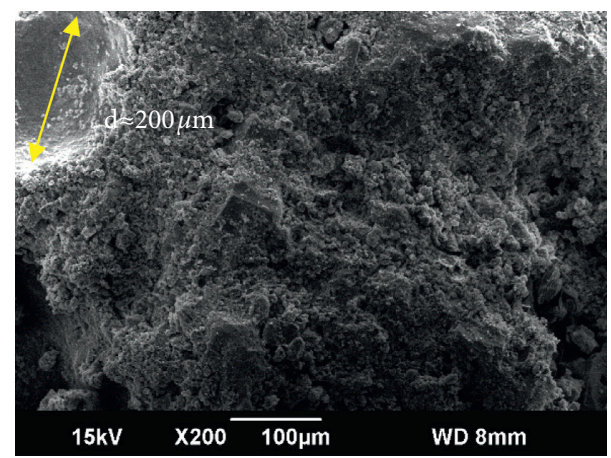

(g)

Figure 6: Pores distribution of $28 \mathrm{~d}$ age CPB formed by slurry with different initial air content. (a) 2.40\%. (b) 4.62\%. (c) 6.03\%. (d) $6.94 \%$. (e) $7.78 \%$. (f) $8.31 \%$. (g) $8.89 \%$. 


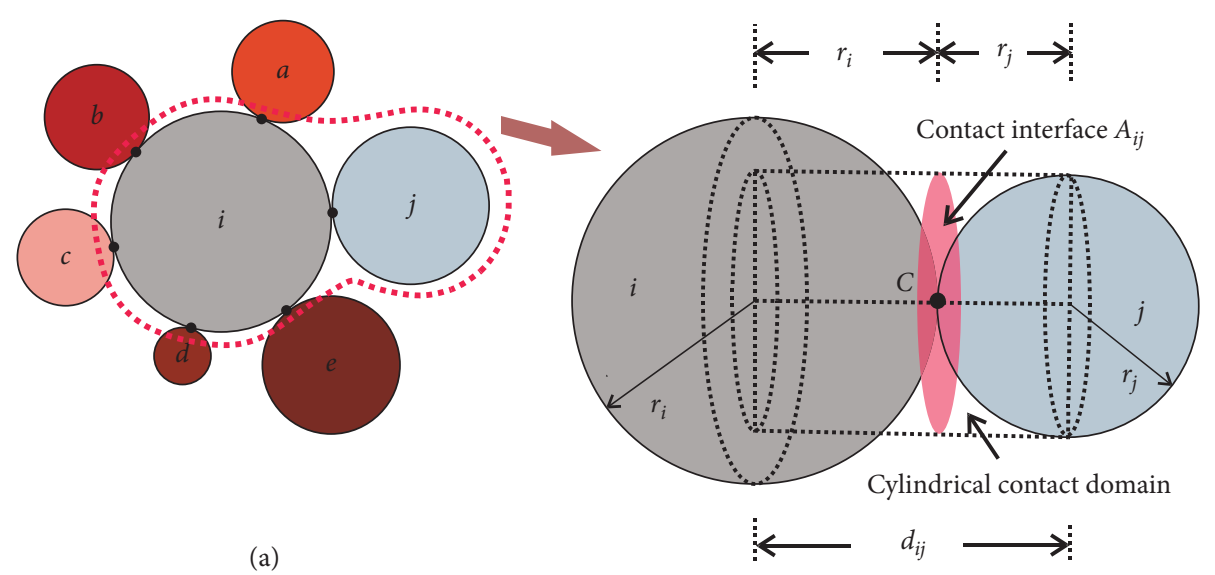

(b)

Figure 7: Schematic diagram of the contact relationship between the particles when the CPB is compressed. (a) The unit-body. (b) Two contacting particles in the unit-body.

$$
F_{i}=m_{i} u_{i}
$$

where $F_{i}$ is the vector force of particle $i, m_{i}$ is the particle mass, and $u_{i}$ is the displacement vector of the centroid of particle $i$, namely, acceleration. Considering the relationship between multiple particles, equation (1) can become

$$
F_{i}=F_{i}^{\mathrm{ext}}+\sum_{j=1}^{n_{i}^{c}} F^{i j}+F_{i}^{\mathrm{damp}}
$$

where $n_{i}{ }^{c}$ is the number of particles in contact with particle $i$, $F_{i}{ }^{\text {ext }}$ represents the external field force, $F^{i j}$ refers to the contact force between particle $i$ and particle $j$, and $F_{i}^{\text {damp }}$ represents the force generated by the particle external damping, which comes from the contact between particle and $\mathrm{C}-\mathrm{S}-\mathrm{H}$. Assuming that the particles are spherical and only a slight overlap between the particles is allowed, the contact condition between particle $i$ and particle $j$ is

$$
d_{i j}=r_{i}+r_{j}
$$

Therefore, the contact interface of two adjacent particles is a circular surface, as shown by $A_{i j}$ in Figure $7(\mathrm{~b})$, and the area of the circle is

$$
\begin{aligned}
A_{i j} & =\pi r_{c}^{2}, \\
r_{c} & =\min \left(r_{i}, r_{j}\right) .
\end{aligned}
$$

When two spherical particles are in contact, the contact force $F^{i j}$ is composed of the normal force $F_{n}{ }^{i j}$ and the shear force $F_{s}{ }^{i j}$. Then, the contact force can be decomposed into

$$
F^{i j}=F_{n}^{i j}+F_{s}^{i j} \text {. }
$$

$F_{n}{ }^{i j}$ and $F_{s}{ }^{i j}$ are derived from the normal stress $\sigma_{n}$ and the shear stress $\sigma_{s} . F_{n}{ }^{i j}$ and $F_{s}{ }^{i j}$ can be calculated by the following formula through the contact area:

$$
\begin{aligned}
& F_{n}^{i j}=A_{i j} \sigma_{n}, \\
& F_{s}^{i j}=A_{i j} \sigma_{s} .
\end{aligned}
$$

For a fixed unit-body, assuming that the number of solid particles and their distribution is fixed, the initial air content only changes the distribution of C-S-H. Then, the higher the initial air content in fresh slurry, the more the C-S-H space occupied by the pores. This will cause the following effects: (i) The damping force $F_{i}^{\text {damp }}$ on the particles is reduced because the particles are exposed to less C-S-H. (ii) The decrease of C-S-H results in the increase of $\sigma_{n}$ and $\sigma_{s}$ when particles are under pressure, while the contact interface $A_{i j}$ does not change. Therefore, it can be seen from equations (6), (7), and (8) that $F^{i j}$ increases. Besides, $F_{i}^{\text {ext }}$ can be considered unchanged in the gravity field. In summary, under the same pressure, as the initial air content in fresh slurry increases, $F_{i}^{\text {damp }}$ decreases, $F^{i j}$ increases, and $F_{i}^{\text {ext }}$ does not change. It can be concluded that the effect of initial air content in fresh slurry on UCS of CPB must be composed of two parts.

Assuming that two functions affect $F_{i}^{\text {damp }}$ and $F^{i j}$, respectively, so from a macro perspective, the effect of initial air content on strength is also composed of two functions. Given the characteristic that the strength first increases and then decreases, in general, there are quadratic function, exponential function, and logarithmic function that can be referred to. Then, the mathematical model should be composed of a pair-wise combination of the three. After screening, it is found that the combination of logarithmic function and quadratic polynomial is the best. The function is $y=-2.90 \ln x-0.106 x^{2}+1.732 x+0.143$ ( $x$ represents the initial air content in fresh slurry, and $y$ represents the $28 \mathrm{~d}$ age UCS of CPB), as shown in Figure 8. The $R^{2}$ is 0.968 , so the reliability is greatly improved compared with single quadratic polynomial $\left(R^{2}=0.889\right)$, which has a greater reference value.

In order to verify the validity of the mathematical model, another two experiments were performed. The airentraining agent dosage was $0.5 \mathrm{~g}(0.026 \%)$ and $1 \mathrm{~g}(0.052 \%)$, respectively, which were different from any experiment in Table 2. The other ratios were the same as Table 2. The results showed that the air content was $6.52 \%, 8.53 \%$ and the $28 \mathrm{~d}$ UCS was $1.46 \mathrm{MPa}$ and $0.90 \mathrm{MPa}$, respectively. The strength 


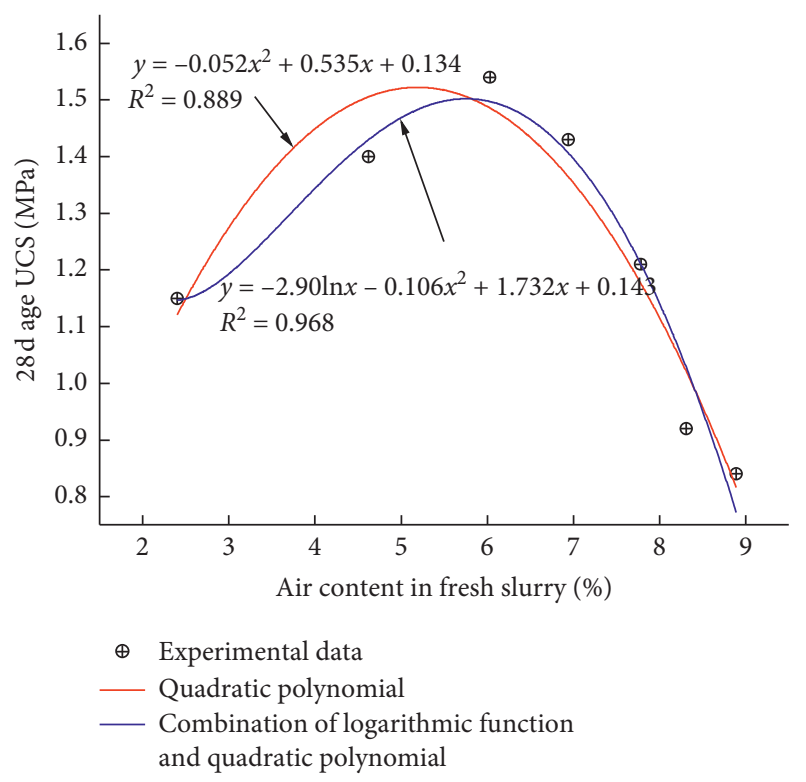

FIgURE 8: Comparison of two mathematical models.

calculated using this model is $1.49 \mathrm{MPa}$ and $0.98 \mathrm{MPa}$, respectively. The error between the calculated value and the test value is calculated by equation (9):

$$
k=\frac{\left|\sigma_{c}-\sigma_{t}\right|}{\sigma_{t}},
$$

where $k$ represents the error, $\sigma_{c}$ represents the calculated value by this model, and $\sigma_{t}$ represents the experimental test value. The error is $2.1 \%$ and $8.9 \%$, respectively, both within $10 \%$, indicating that the model has good practicability.

\section{Conclusions}

The main conclusions of this paper are as follows:

(1) The influence of SDS dosage on the initial air content in fresh slurry is a quadratic polynomial.

(2) In the UCS experiment, some samples show fluctuations near the peak of the stress-displacement curve, and this phenomenon does not become obvious after the initial air content is higher than $6.94 \%$

(3) As the initial air content in fresh slurry increases, the $28 \mathrm{~d}$ age UCS of CPB first increases and then decreases, and the initial air content of $6.03 \%$ can provide the optimal UCS for CPB.

(4) Before the initial air content of $6.03 \%$, the microstructure of $\mathrm{CPB}$ is relatively compact. After this value, "discontinuous contact" structure, pore groups, and macropores will appear inside the CPB. The diameter of the largest pore can reach $200 \mu \mathrm{m}$. These are the reasons to reduce the UCS of CPB.

(5) The mathematical model to describe the effect of initial air content in fresh slurry on the $28 \mathrm{~d}$ age UCS of CPB is composed of a logarithmic function and a quadratic polynomial. However, this mathematical model does not include changes in gradation, concentration, and cement/sand ratio. The next work is to incorporate more factors into the model.

\section{Data Availability}

The data supporting the findings of this study are included in the article. Additionally, raw data generated during the study are available from the corresponding author upon request.

\section{Conflicts of Interest}

The authors declare that they have no conflicts of interest.

\section{Acknowledgments}

This work was supported by the National Natural Science Foundation of China (Project no. 51774137), the Natural Science Foundation of Hebei Province, China (Project no. E2019209326), the Graduate Student Innovation Fund of North China University of Science and Technology (Project no. CXZZBS2020137), and the Science and Technology Project of Tangshan City (Project no. 20130207b).

\section{References}

[1] Z. Xue, D. Gan, Y. Zhang, and Z. Liu, "Rheological behavior of ultrafine-tailings cemented paste backfill in high-temperature mining conditions," Construction and Building Materials, vol. 253, Article ID 119212, 2020.

[2] M. Fall, M. Benzaazoua, and S. Ouellet, "Experimental characterization of the influence of tailings fineness and density on the quality of cemented paste backfill," Minerals Engineering, vol. 18, no. 1, pp. 41-44, 2005.

[3] X. Chen, X. Shi, J. Zhou, X. Du, Q. Chen, and X. Qiu, "Effect of overflow tailings properties on cemented paste backfill," Journal of Environmental Management, vol. 235, pp. 133-144, 2019.

[4] L. Yang, H. Wang, A. Wu et al., "Effect of mixing time on hydration kinetics and mechanical property of cemented paste backfill," Construction and Building Materials, vol. 247, Article ID 118516, 2020.

[5] S. Yin, Y. Shao, A. Wu, H. Wang, X. Liu, and Y. Wang, "A systematic review of paste technology in metal mines for cleaner production in China," Journal of Cleaner Production, vol. 247, Article ID 119590, 2020.

[6] F. Cihangir and Y. Akyol, "Effect of desliming of tailings on the fresh and hardened properties of paste backfill made from alkali-activated slag," Advances in Materials Science and Engineering, vol. 2020, Article ID 4536257, 11 pages, 2020.

[7] F. Wang, G. Chen, L. Ji, and Z. Yuan, "Preparation and mechanical properties of cemented uranium tailing backfill based on alkali-activated slag," Advances in Materials Science and Engineering, vol. 2020, Article ID 6345206, 7 pages, 2020.

[8] X. Zhou, S. Hu, G. Zhang, J. Li, D. Xuan, and W. Gao, "Experimental investigation and mathematical strength model study on the mechanical properties of cemented paste backfill," Construction and Building Materials, vol. 226, pp. 524-533, 2019.

[9] J. Wu, M. Feng, G. Han, X. Ni, and Z. Chen, "Experimental investigation on mechanical properties of cemented paste backfill under different gradations of aggregate particles and types and contents of cementing materials," Advances in 
Materials Science and Engineering, vol. 2019, Article ID 9456861, 11 pages, 2019.

[10] Y.-y. Tan, X. Yu, D. Elmo, L.-h. Xu, and W.-d. Song, "Experimental study on dynamic mechanical property of cemented tailings backfill under SHPB impact loading," International Journal of Minerals, Metallurgy, and Materials, vol. 26, no. 4, pp. 404-416, 2019.

[11] B. Yan, F. Ren, M. Cai, and C. Qiao, "Influence of new hydrophobic agent on the mechanical properties of modified cemented paste backfill," Journal of Materials Research and Technology, vol. 8, no. 6, pp. 5716-5727, 2019.

[12] R. Gao, K. Zhou, W. Liu, and Q. Ren, "Correlation between the pore structure and water retention of cemented paste backfill using centrifugal and nuclear magnetic resonance methods," Minerals, vol. 10, no. 7, p. 610, 2020.

[13] H. Rong, M. Zhou, and H. Hou, "Pore structure evolution and its effect on strength development of sulfate-containing cemented paste backfill," Minerals, vol. 7, no. 1, p. 8, 2017.

[14] J. H. Hu, Y. Kuang, T. Zhou, and F. Zhao, "Influence of air entraining agent on strength and microstructure properties of cemented paste backfill," IEEE Access, vol. 7, pp. 140899140907, 2019.

[15] J. Hu, F. Zhao, Y. Kuang, D. Yang, M. Zheng, and L. Zhao, "Microscopic characteristics of the action of an air entraining agent on cemented paste backfill pores," Alexandria Engineering Journal, vol. 59, no. 3, pp. 1583-1593, 2020.

[16] E. K. K. Nambiar and K. Ramamurthy, "Air-void characterisation of foam concrete," Cement and Concrete Research, vol. 37, no. 2, pp. 221-230, 2007.

[17] Y. Xie, J. Li, Z. Lu, J. Jiang, and Y. Niu, "Effects of bentonite slurry on air-void structure and properties of foamed concrete," Construction and Building Materials, vol. 179, pp. 207-219, 2018.

[18] P. Du, Y. Yao, L. Wang et al., "Using strain to evaluate influence of air content on frost resistance of concrete," Cold Regions Science and Technology, vol. 157, pp. 21-29, 2019.

[19] Q. Yang, P. Zhu, X. Wu, and S. Huang, "Properties of concrete with a new type of saponin air-entraining agent," Cement and Concrete Research, vol. 30, no. 8, pp. 1313-1317, 2000.

[20] T. S. Yun, K. Y. Kim, and D. H. Kang, "Quantifying the distribution of paste-void spacing of hardened cement paste using X-ray computed tomography," Materials Characterization, vol. 73, pp. 137-143, 2012.

[21] H. Jianhua, Q. Jiang, and Q. Ren, "Cross scale correlation characteristics of pore structure and meso parameters of filling body," The Chinese Journal of Nonferrous Metals, vol. 28, no. 10, pp. 2154-2163, 2018.

[22] F. Özcan and M. Emin Koç, "Influence of ground pumice on compressive strength and air content of both non-air and air entrained concrete in fresh and hardened state," Construction and Building Materials, vol. 187, pp. 382-393, 2018.

[23] A. A. Hilal, N. H. Thom, and A. R. Dawson, "On void structure and strength of foamed concrete made without/with additives," Construction and Building Materials, vol. 85, pp. 157-164, 2015.

[24] T. T. Nguyen, H. H. Bui, T. D. Ngo, and G. D. Nguyen, "Experimental and numerical investigation of influence of airvoids on the compressive behaviour of foamed concrete," Materials \& Design, vol. 130, pp. 103-119, 2017. 